\title{
Comparison between classic survival analysis methods and competing risks for analysis of competing events
}

\author{
Comparação entre métodos de análise de sobrevivência clássica e riscos \\ competitivos para análise de eventos competitivos
}

\section{Flávia Sílvia Corrêa TOMAZ1; Sebastião MARTINS FILHO²; Leandro Roberto de MACEDO³; Cristiane Márcia dos SANTOS ${ }^{4}$}

\begin{abstract}
1 Doutora em Estatística Aplicada e Biometria, Universidade Federal de Ouro Preto (UFOP), Departamento de Ciências Administrativas (DECAD). Instituto de Ciências Sociais Aplicadas (ICSA), Rua do Catete, 166, Mariana, Minas Gerais, 354200-000. flaviastomaz@yahoo.com.br (Autora para correspondência)

${ }^{2}$ Doutor em Genética e Melhoramento, Universidade Federal de Viçosa (UFV)

${ }^{3}$ Doutor em Estatística Aplicada e Biometria, Universidade Federal de Juiz de Fora (UFJF), leandro.macedo@ufj..edu.br

${ }^{4}$ Doutora em Economia Aplicada, Universidade Federal de Ouro Preto (UFOP), crikamarcia@hotmail.com
\end{abstract}

Recebido em: 14-05-2018; Aceito em: 05-02-2019

\begin{abstract}
This study compares two different methods for survival data analysis in the presence of competing events. The first method focused on standard survival analysis, more specifically on obtaining cumulative incidence by using the Kaplan-Meier estimator, modeling the effect of covariates by fitting the Cox proportional hazards model. Competing events were treated as censoring events. The second method, called competing risks, emphasized the achievement of cumulative incidence, modeling the effect of covariates based on the cumulative incidence function and the Fine and Gray model, respectively. To illustrate and compare these two methods, we used data on racehorse injuries. This study considered the following events: injuries due to claudication (main event) and injuries due to other causes (competing event). The results indicated that the incidence for each of the events was overestimated when using the Kaplan-Meier estimator. Moreover, the modeling of covariate effects on specific risk fitted by the Cox model did not correspond to the effect on the incidence of this event fitted by the Fine and Gray model.
\end{abstract}

Additional keywords: Cox Model; Fine and Gray Model; Kaplan-Meier.

\section{Resumo}

O objetivo deste trabalho foi confrontar duas distintas abordagens na análise de dados de sobrevivência na presença de eventos competitivos. A primeira abordagem focou-se na análise de sobrevivência padrão, mais especificadamente, na obtenção da incidência cumulativa por meio do uso do complemento do estimador de Kaplan-Meier, e na modelagem do efeito das covariáveis pelo ajuste do modelo de riscos proporcionais de Cox. Nesta abordagem, os eventos competitivos foram tratados como censura. A segunda abordagem, denominada riscos competitivos, enfatizou a obtenção da incidência cumulativa e a modelagem do efeito das covariáveis, tendo como base, respectivamente, a função de incidência cumulativa e o modelo de Fine e Gray. Para a ilustração e a comparação destas duas metodologias, utilizou-se de dados referentes a lesões em equinos de corrida. Os eventos considerados neste estudo foram lesões devido à claudicação (evento principal) e lesões decorrente de outras injúrias (evento competitivo). Os resultados encontrados indicaram que a estimativa da incidência para cada um dos eventos, quando se utilizou do estimador de Kaplan-Meier, foi superestimada. Além disso, a modelagem dos efeitos das covariáveis sobre o risco específico, ajustado pelo modelo de Cox, não correspondeu ao efeito sobre a incidência deste evento ajustado pelo modelo de Fine e Gray.

Palavras-chave adicionais: Kaplan-Meier; Modelo de Cox; Modelo de Fine e Gray.

\section{Introduction}

A classic problem in modeling survival times is failure due to several distinct events, called competing events, which introduce competing risks (Aalen et al., 2008). Although there are different types of failures, it is possible to observe the time until the occurrence of the first event, preventing others from happening (Carvalho et al., 2011) or fundamentally altering the probability of occurrence of these other types of events (Gooley et al. 1999). Thus, the competing risk structure can be used if different types of events are studied focusing on the time and type of the first event (Wolbers et al., 2014; Beyersmann et al., 2012).

In competing risk analysis, the calculation of the incidence function as well as the measurement of 
the effects of covariates are often of interest (Kim, 2007). The cumulative incidence function represents the probability of an event occurring, and the estimation of this quantity in survival analysis without competing risks is obtained by means of the complement of the survival function, that is, by $1-\hat{S}(t)$, where $\hat{S}(t)$ is obtained by using the Kaplan-Meier estimator. However, in the presence of competing events, studies have pointed to the inadequacy of this estimator in obtaining cumulative incidence for a specific cause (Andersen et al., 2012; Kim, 2007; Gooley et al., 1999).

In the presence of competing risks, the incidence based on the Kaplan-Meier estimator is overestimated (Carvalho et al., 2011). This occurs because this estimator ignores all events other than that of interest, considering them as censoring events. To overcome this problem, we use the cumulative incidence function, also called subdistribution, which estimates the probability of occurrence of an event of interest without disregarding the competing event.

In many applications, competing risks have been ignored when modeling covariate effects, fitting the Cox regression model (Wolbers et al., 2009). Thus, the Cox model models the cause-specific hazard for the kth event, $\lambda_{k}(t)$, given by:

$\lambda_{k}(t)=\lim _{\Delta t \rightarrow 0}\left\{\frac{P(t \leq T<t+\Delta t, \varepsilon=k \mid T \geq t)}{\Delta t}\right\}$

and represents the probability of an individual failing in a short time interval.

In this model, competing risks are ignored and, therefore, the covariate effect reflects the "pure" effect, or rather, the effect when other types of events do not exist (Pintilie, 2006). Furthermore, the covariate effect on the cause-specific hazard of an event, when using the Cox model, may differ from the covariate effect on the incidence of this event when considering the competing risk (Kim, 2007). As the Cox model does not have a direct interpretation in terms of the incidence function (Scrucca et al., 2010), Fine \& Gray (1999) proposed a model for cumulative incidence risk. This model allows to directly evaluate the effect of covariates on the cumulative incidence function.

Thus, the present study compares the approach based on standard survival analysis with the approach based on competing risks in the estimation of cumulative incidence, also comparing the standard Cox regression model with the Fine and Gray model in the modeling of data on racehorse injuries.

\section{Materials and methods}

The data used in this study refer to 158 English Thoroughbred (ETB) horses that remained in the Training Center in Pedro do Rio, Petrópolis city, RJ State, from January 2001 to December 2003. The response variable is the time until the first failure, the main event was failure due to claudication, while the competing event was failure due to other injuries. Of the 158 animals, 90 (57\%) experienced the main event (claudication), 27 (17.1\%) experienced the competing event (other injuries), and 41 (25.9\%) had not experienced none of the events, that is, were censored.

Based on the Kaplan-Meier estimator, the total probability of occurrence of an event, regardless of type of injury, was obtained using the expression $\hat{F}(t)=1-$ $\hat{S}(t)$, where $\hat{S}(t)$ is the event-free survival provided by the Kaplan-Meier estimator (1958), defined as:

$\hat{S}(t)=\prod_{j: t_{j}<t}\left(1-\frac{d_{j}}{n_{j}}\right)$

where $d_{j}$ is the number of failures in $t_{j}, \mathrm{j}=1,2, \ldots, r, \mathrm{r}$ distinct times, and $n_{j}$ is the number of individuals at risk in $t_{j}$ (Geskus, 2015; Carvalho et al., 2011; Colosimo \& Giolo, 2006).

Alternatively, we estimated the total probability of occurrence of an injury by estimating the incidence function, given by the sum of incidences for each type of event. The total incidence is given by the expression:

$$
\begin{aligned}
F(t)=P(T \leq t) & = \\
& =\sum_{k=1}^{2} P(T \leq t, \varepsilon=k)= \\
& =F_{1}(t)+F_{2}(t)
\end{aligned}
$$

in which $k$ is the event type, $k=1,2$, where $k=1$ refers to the main event and $k=2$ corresponds to the competing event; $F_{1}(t)$ and $F_{2}(t)$ are, respectively, the probabilities of claudication and injury due to other causes, and are estimated by:

$$
\hat{F}_{k}(t)=\sum_{\forall j, t_{j}<t} \frac{d_{i j}}{n_{j}} \hat{S}\left(t_{j-1}\right)
$$

wherein, $k=1,2, d_{i j}$ represents the number of animals that experienced event $\mathrm{k}$ at time $t_{j}, n_{j}$ is the number of animals at risk at time $t_{j}$, and $\hat{S}\left(t_{j-1}\right)$ is the event-free survival at time $t_{j-1}$, obtained as described in (1) (Pintilie, 2006).

The incidence of each event, $\hat{F}_{k}(t)=P(T \leq t$, $\varepsilon=k$ ), was estimated in two distinct ways. In the first one, $\widehat{F}_{k}(t)$ was obtained as the complement of the Kaplan-Meier estimator for event $k$, that is, $\hat{F}_{k}(t)=1-K M_{k}$, where $K M_{k}$ is the Kaplan-Meier estimator for the kth event, given by expression (1), obtained by considering the event distinct from $\mathrm{k}$ as censoring. The second way of obtaining the probability of experiencing the kth event, $\hat{F}_{k}(t)=P(T \leq t, \varepsilon=$ $=k$ ), was based on the incidence function approach when competing risks are present, as presented in expression (3). Then, two different regression models were fitted: the Cox model for cause-specific hazard and the Fine and Gray model for subdistribution hazard. 
The semiparametric Cox proportional hazards model fitted for cause-specific hazard for each type of event is given by:

$$
\lambda_{k}(t \mid Z)=\lambda_{k, 0} \exp \left(\beta_{k}^{T} Z_{i}\right)
$$

wherein, $\beta_{k}$ is the $\mathrm{p} \times 1$ vector of regression coefficients, $Z_{i}$ is the $\mathrm{p} \times 1$ vector of covariates, and $\lambda_{k, 0}$ is the baseline hazard function for cause $k$, nonnegative and unspecified (Geskus, 2015; Crowder, 2001).

The model of hazards proportional to the subdistribution hazards proposed by Fine \& Gray (1999) can be written as:

$$
\gamma_{k}(t \mid Z)=\gamma_{k 0} \exp \left(\beta_{k}^{T} Z_{i}\right)
$$

wherein, $\beta_{k}$ is the $\mathrm{p} \times 1$ vector of regression coefficients, $Z_{i}$ is the $\mathrm{p} \times 1$ vector of covariates, and $\gamma_{k, 0}$ is the baseline hazard subdistribution for cause $k$, nonnegative and unspeciied.

The covariates that had their effects evaluated were: sex ( 1 for female and 2 for male); age (months); weight, categorical variable, defined as 1 if the weight of the animal is less than $480 \mathrm{~kg}$ and 2 if the weight of the animal is greater than or equal to $480 \mathrm{~kg}$; training stations (number of training stations). Data were analyzed in $R$ software ( $R$ Development Core Team, 2016), using the survfit and coxph functions of the survival package and the cuminc and crr functions of the cmprsk package.

\section{Results and discussion}

Of the 158 horses in the study, 62 (39.2\%) were female and $96(60.8 \%)$ male. The age of the animals ranged from 25 months to 75 months, with 120 animals $(75.9 \%)$ in the range from 25 months to 36 months, and $38(24.1 \%)$ animals more than 36 months old. The mean age was 32.6 months. Sixty-seven animals $(42.4 \%$ ) weighed less than $480 \mathrm{~kg}$, and ninetyone $(57.6 \%)$ weighed $480 \mathrm{~kg}$ or more. The number of training stations ranged from 1 to 6 stations, with a median value of 2 .

Cumulative incidence functions (CIF) for claudication and other injuries are shown in Figure 1 along with the total incidence, i.e., incidence of any injury regardless of type.

The total cumulative incidence, $1-\hat{S}(t)$, estimated by the complement of the Kaplan-Meier function for injury-free survival is shown in Figure 1. This incidence is equal to the sum of cumulative incidences for claudication and other types of injuries (Table 1). This analysis of the event of interest as a single type of failure event is correct, but limited to evaluate several important research questions (Kim, 2007). In this direction, the analysis of the combination of different causes of failure and the subsequent analysis as a single event responds to the questions related to the differences between groups and/or treatments considering the combination of event types, although not allowing to compare the cumulative incidence for the different types of events.

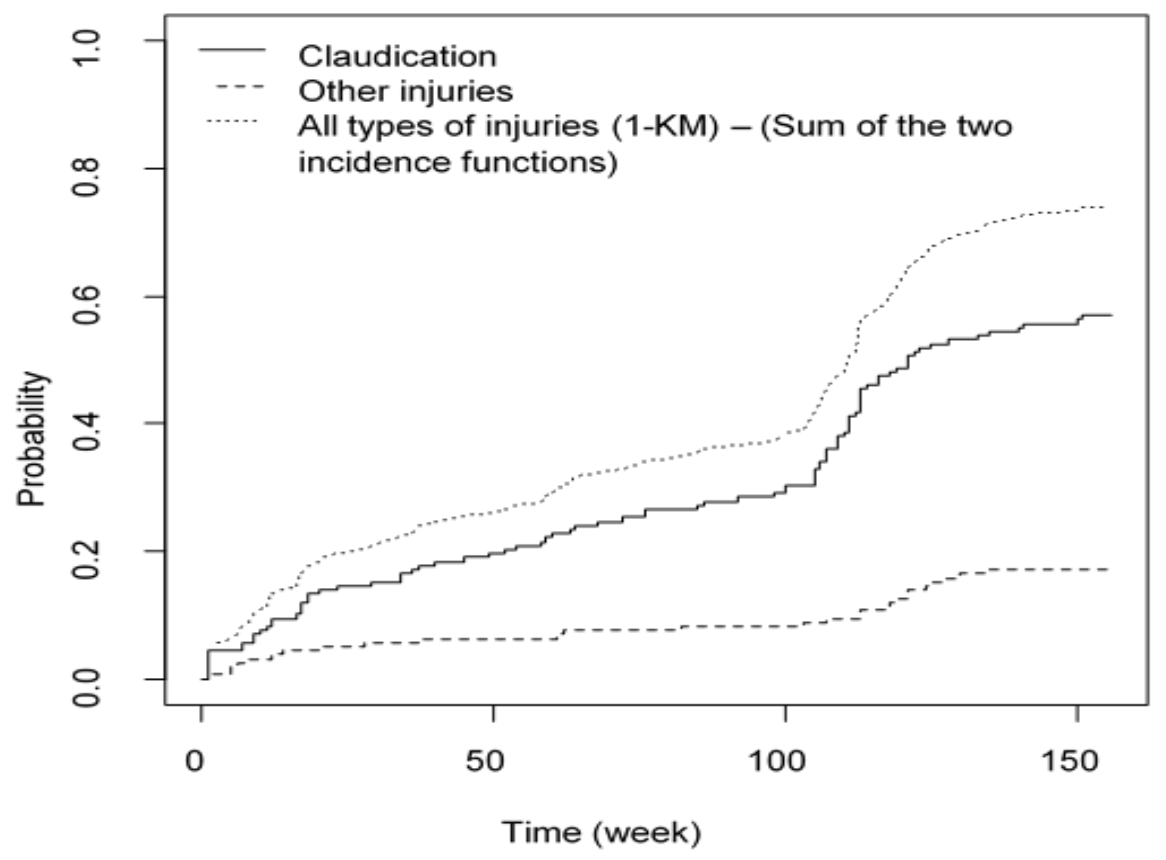

Figure 1 - Cumulative incidence function for claudication, cumulative incidence function for other injuries and the Kaplan-Meier (KM) estimator for the incidence of all types of injuries (sum of the two incidence functions). 
Table 1 - Estimated incidences for claudication $\left(\widehat{\boldsymbol{F}}_{\mathbf{1}}(\boldsymbol{t})\right)$, for other injuries $\left(\widehat{\boldsymbol{F}}_{\mathbf{2}}(\boldsymbol{t})\right)$, for the total incidence $(\widehat{\boldsymbol{F}}(\boldsymbol{t}))$ and for the calculated incidence based on the Kaplan-Meier estimator $(\mathbf{1}-\widehat{\boldsymbol{S}}(\boldsymbol{t}))$.

\begin{tabular}{|c|c|c|c|c|c|c|c|c|c|}
\hline $\begin{array}{c}\begin{array}{c}\text { Time } \\
\text { (week) }\end{array} \\
\end{array}$ & $\hat{F}_{1}(t)$ & $\hat{F}_{2}(t)$ & $\hat{F}(t)=\hat{F}_{1}(t)+\hat{F}_{2}(t)$ & $1-\hat{S}(t)$ & $\begin{array}{c}\text { Time } \\
\text { (week) }\end{array}$ & $\hat{F}_{1}(t)$ & $\hat{F}_{2}(t)$ & $\hat{F}(t)=\hat{F}_{1}(t)+\hat{F}_{2}(t)$ & $1-\hat{S}(t)$ \\
\hline 1 & 0.0443 & 0.0063 & 0.0506 & 0.0506 & 82 & 0.2658 & 0.0823 & 0.3481 & 0.3481 \\
\hline 5 & 0.0443 & 0.0190 & 0.0633 & 0.0633 & 85 & 0.2722 & 0.0823 & 0.3544 & 0.3544 \\
\hline 6 & 0.0443 & 0.0253 & 0.0696 & 0.0696 & 86 & 0.2785 & 0.0823 & 0.3608 & 0.3608 \\
\hline 7 & 0.0570 & 0.0253 & 0.0823 & 0.0823 & 92 & 0.2848 & 0.0823 & 0.3671 & 0.3671 \\
\hline 8 & 0.0570 & 0.0316 & 0.0886 & 0.0886 & 98 & 0.2911 & 0.0823 & 0.3734 & 0.3734 \\
\hline 9 & 0.0696 & 0.0316 & 0.1013 & 0.1013 & 100 & 0.3038 & 0.0823 & 0.3861 & 0.3861 \\
\hline 10 & 0.0759 & 0.0316 & 0.1076 & 0.1076 & 103 & 0.3038 & 0.0886 & 0.3924 & 0.3924 \\
\hline 11 & 0.0823 & 0.0316 & 0.1139 & 0.1139 & 105 & 0.3291 & 0.0886 & 0.4177 & 0.4177 \\
\hline 12 & 0.0949 & 0.0380 & 0.1329 & 0.1329 & 106 & 0.3418 & 0.0886 & 0.4304 & 0.4304 \\
\hline 14 & 0.0949 & 0.0443 & 0.1392 & 0.1392 & 107 & 0.3608 & 0.0949 & 0.4557 & 0.4557 \\
\hline 16 & 0.1013 & 0.0443 & 0.1456 & 0.1456 & 109 & 0.3797 & 0.0949 & 0.4747 & 0.4747 \\
\hline 17 & 0.1203 & 0.0443 & 0.1646 & 0.1646 & 110 & 0.3861 & 0.0949 & 0.4810 & 0.4810 \\
\hline 18 & 0.1329 & 0.0443 & 0.1772 & 0.1772 & 111 & 0.4114 & 0.0949 & 0.5063 & 0.5063 \\
\hline 20 & 0.1392 & 0.0443 & 0.1835 & 0.1835 & 112 & 0.4177 & 0.0949 & 0.5127 & 0.5127 \\
\hline 21 & 0.1392 & 0.0506 & 0.1899 & 0.1899 & 113 & 0.4557 & 0.1076 & 0.5633 & 0.5633 \\
\hline 23 & 0.1456 & 0.0506 & 0.1962 & 0.1962 & 114 & 0.4620 & 0.1076 & 0.5696 & 0.5696 \\
\hline 28 & 0.1456 & 0.0570 & 0.2025 & 0.2025 & 116 & 0.4747 & 0.1076 & 0.5823 & 0.5823 \\
\hline 29 & 0.1519 & 0.0570 & 0.2089 & 0.2089 & 117 & 0.4747 & 0.1139 & 0.5886 & 0.5886 \\
\hline 34 & 0.1646 & 0.0570 & 0.2215 & 0.2215 & 118 & 0.4810 & 0.1203 & 0.6013 & 0.6013 \\
\hline 36 & 0.1709 & 0.0570 & 0.2278 & 0.2278 & 119 & 0.4873 & 0.1266 & 0.6139 & 0.6139 \\
\hline 37 & 0.1772 & 0.0633 & 0.2405 & 0.2405 & 121 & 0.5063 & 0.1392 & 0.6 & 0.6456 \\
\hline 40 & 0.1835 & 0.0633 & 0.2468 & 0.2468 & 122 & 0.5127 & 0.1392 & 0.6519 & 0.6519 \\
\hline 45 & 0.1899 & 0.0633 & 0.2532 & 0.2532 & 123 & 0.5190 & 0.1392 & 0.6582 & 0.6582 \\
\hline 52 & 0.2025 & 0.0633 & 0.2658 & 0.2658 & 125 & 0.5253 & 0.1519 & 0.6772 & 0.6772 \\
\hline 54 & 0.2025 & 0.0633 & 0.2658 & 0.2658 & 127 & 0.5253 & 0.1582 & 0.6835 & 0.6835 \\
\hline 58 & 0.2152 & 0.0633 & 0.2785 & 0.2785 & 128 & 0.5316 & 0.1582 & 0.6899 & 0.6899 \\
\hline 59 & 0.2215 & 0.0633 & 0.2848 & 0.2848 & 130 & 0.5316 & 0.1646 & 0.6962 & 0.6962 \\
\hline 60 & 0.2278 & 0.0633 & 0.2911 & 0.2911 & 133 & 0.5380 & 0.1646 & 0.7025 & 0.7025 \\
\hline 61 & 0.2278 & 0.0696 & 0.2975 & 0.2975 & 135 & 0.5443 & 0.1709 & 0.7152 & 0.7152 \\
\hline 62 & 0.2278 & 0.0759 & 0.3038 & 0.3038 & 140 & 0.5506 & 0.1709 & 0.7215 & 0.7215 \\
\hline 63 & 0.2342 & 0.0759 & 0.3101 & 0.3101 & 141 & 0.5570 & 0.1709 & 0.7278 & 0.7278 \\
\hline 64 & 0.2405 & 0.0759 & 0.3165 & 0.3165 & 150 & 0.5633 & 0.1709 & 0.7342 & 0.7342 \\
\hline 68 & 0.2468 & 0.0759 & 0.3228 & 0.3228 & 151 & 0.5696 & 0.1709 & 0.7405 & 0.7405 \\
\hline 72 & 0.2532 & 0.0759 & 0.3291 & 0.3291 & 156 & 0.5696 & 0.1709 & 0.7405 & 0.7405 \\
\hline 76 & 0.2658 & 0.0759 & 0.3418 & 0.3418 & - & & - & - & - \\
\hline
\end{tabular}

The sum of the Kaplan-Meier estimates for claudication and other injuries is greater than the estimate of the total incidence, obtained by the sum of the two incidence functions (Figure 2). These curves illustrate the incorrect estimate of the total incidence when using the sum of Kaplan-Meier estimators of distinct events to estimate this function.

The overestimation of CIF when using the sum of Kaplan-Meier estimates for different events is reported by Austin et al. (2016) in their study on causes of death (cardiovascular and noncardiovascular causes) in patients with cardiovascular disease.

Figures 3 and 4 show, respectively, the incidence probabilities for claudication and other injuries, obtained through the complement of the Kaplan-Meier estimator, and the estimates obtained based on the incidence function for each of the events. 


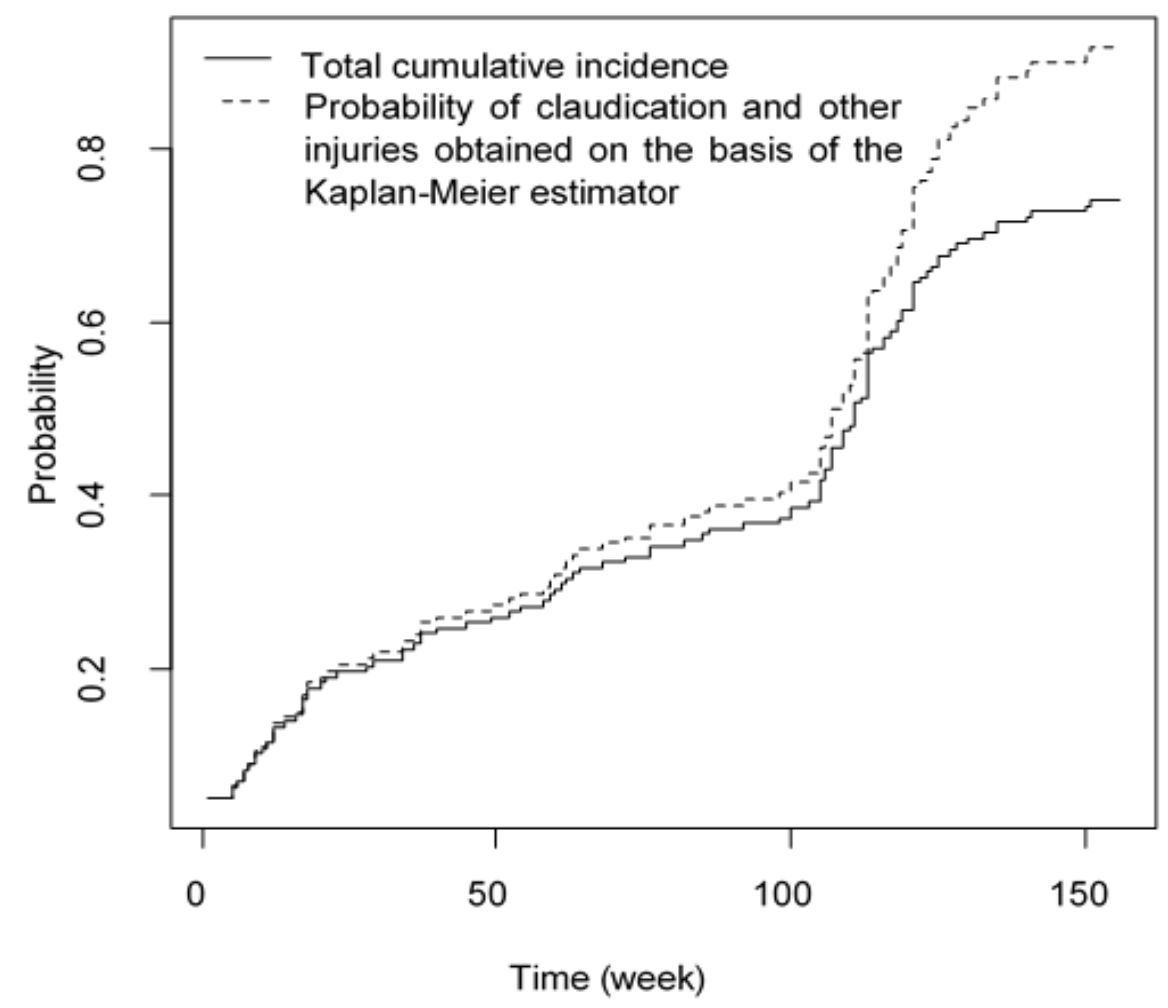

Figure 2 - Total cumulative incidence function and incidence calculated by the sum of the estimates of the probability of claudication and other injuries obtained on the basis of the Kaplan-Meier estimator.

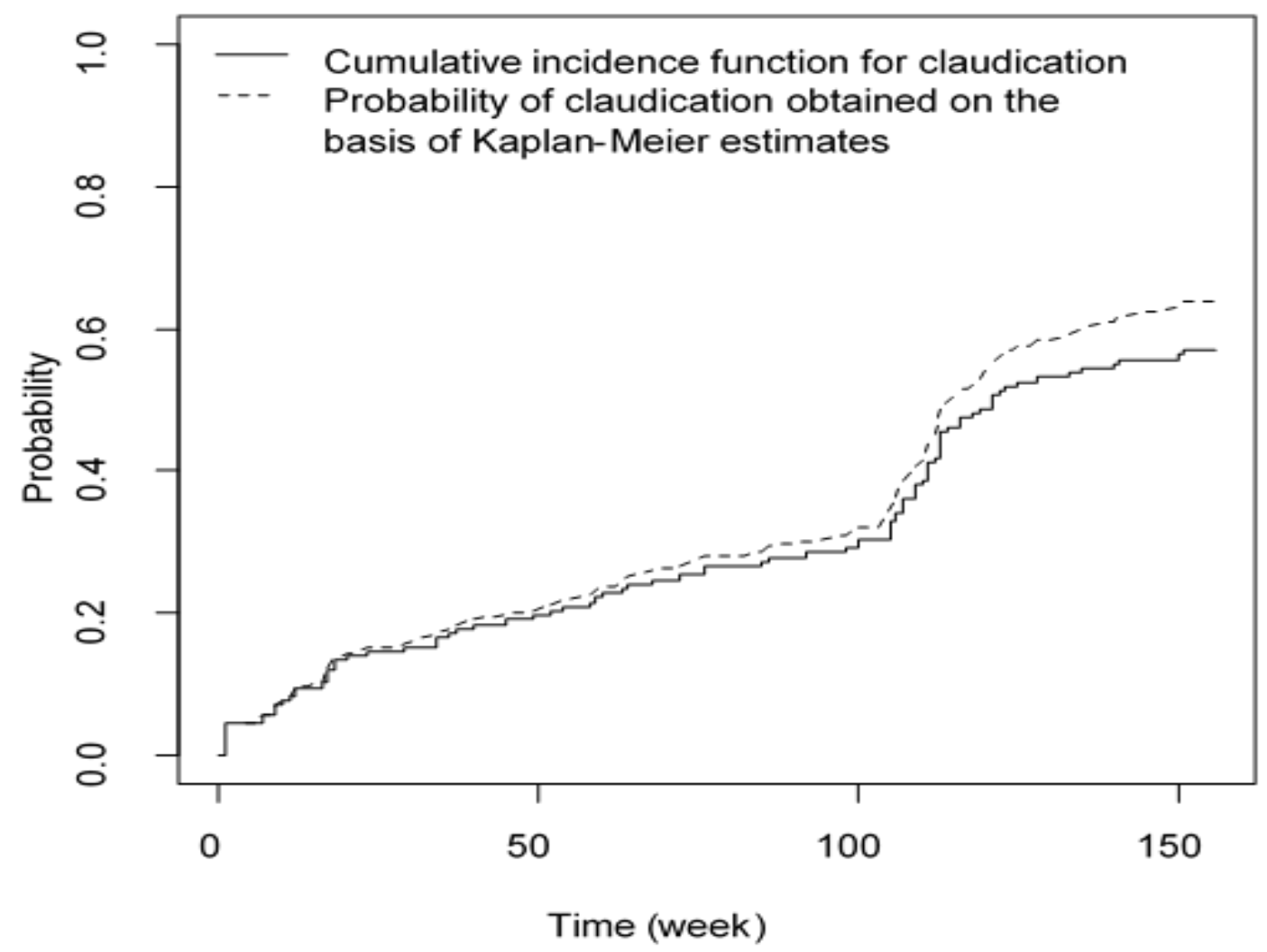

Figure 3 - Cumulative incidence function for claudication and probability of claudication obtained on the basis of Kaplan-Meier estimates. 


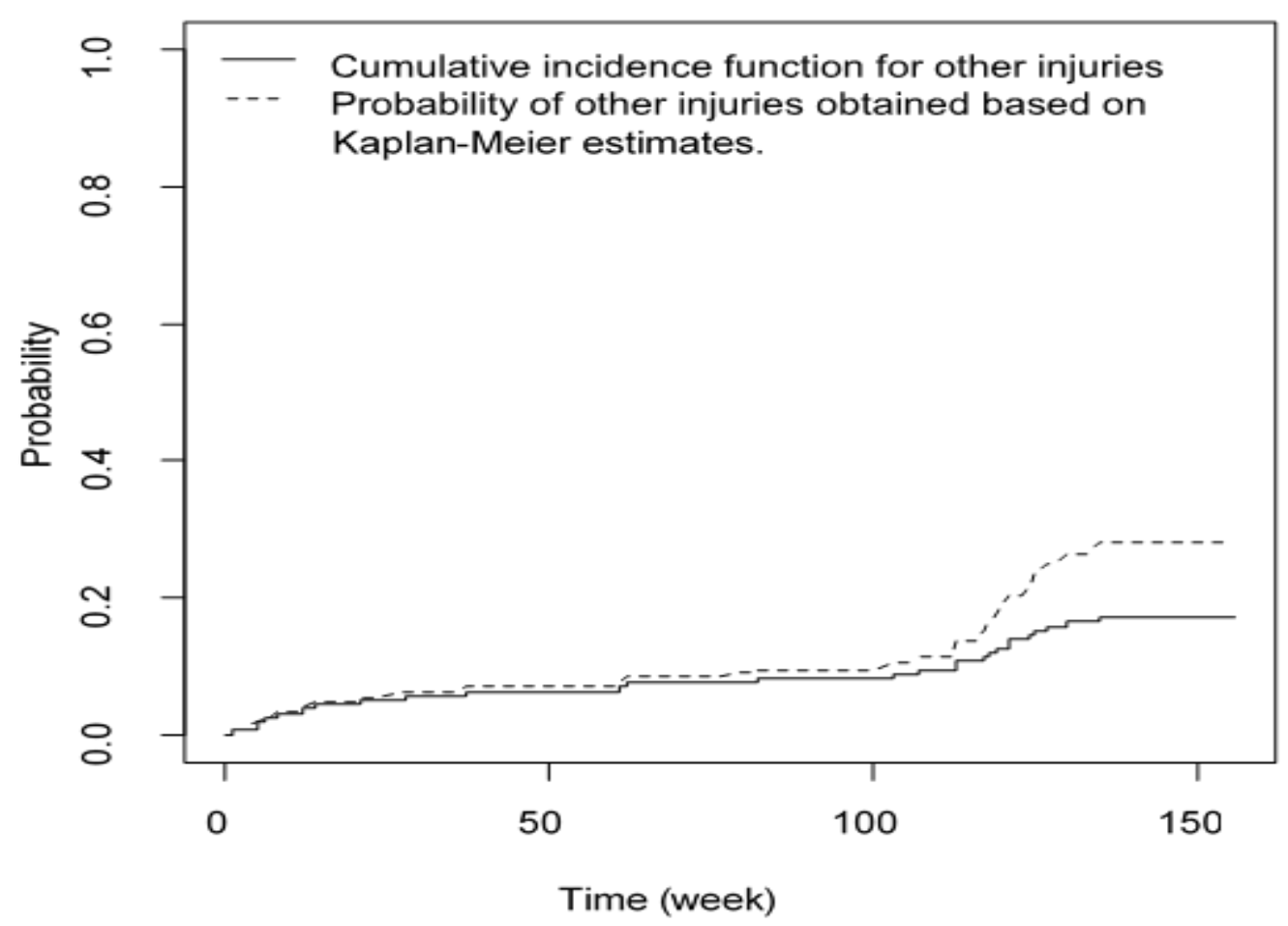

Figure 4 - Cumulative incidence function for other injuries and probability of other injuries obtained based on Kaplan-Meier estimates.

The probability curves obtained based on the Kaplan-Meier estimator for both events are equal to or greater than the estimates obtained from the cumulative incidence function. Hence, there is also an overestimation of the incidences for each type of event, and the bias increases with animal follow-up time.

Assane et al. (2015) also highlighted the limitations of the classic Kaplan-Meier estimator when applied to estimate the incidence of different types of events (nonfatal cardiovascular event, death due to cardiovascular causes, death due to another cause) in patients with arterial hypertension. According to the aforementioned authors, the probability of failure for an event of interest estimated using the Kaplan-Meier estimator is equal to or greater than the probability estimated based on the cumulative incidence function. These authors, as well as Berry et al. (2010), also emphasized that the magnitude of the bias increases with increased patient follow-up time, which agrees with the results found in this study. The bias is a consequence of both the treatment of competing events as censors and the estimation of the incidence of the event of interest based on the Kaplan-Meier estimator. When estimating incidence using this procedure, the assumption underlying the Kaplan-Meier estimator is violated: the independence between the event time and the censoring distribution (Putter et al., 2007).

In the calculation used for the Kaplan-Meier estimator, censoring the event time of an individual indicates that the subject has not yet experienced the event of interest until the censoring time, but may experience this event at a later time, unobservable (Wolbers et al., 2014). Consequently, censored individuals can be represented by those who remain under observation; thus, the risk is equal for censored individuals and for those who remained under observation (Putter et al., 2007).

However, in the competing risk structure, individuals who experience a competing event have never experienced the event of interest as the first event (Wolbers et al., 2014). Individuals who did not fail due to the event of interest are treated as if they could still experience this type of event, i.e., they are censored; thus, the Kaplan-Meier estimator eventually overestimates the likelihood of failure (Putter et al., 2007).

The impact of the incorrect treatment of competing events as censored events is of practical importance, since, in general, the greater the percentage of competing events the greater the bias (Austin et al., 2016; Wolbers et al., 2014).

The results of this work point out that the estimates of the cumulative incidence functions for the two considered events, claudication and other injuries, based on the Kaplan-Meier estimator, that is, ignoring the competitive risk structure, were biased, which corroborates the results found in the literature (Logan et al., 2006; Kim, 2007; Putter et al., 2007; Andersen et al., 2012).

The results of the regression models for cause-specific hazard and for subdistribution hazard are presented in Table 2. 
Table 2 - Estimates obtained for the Fine and Gray regression models for the cumulative incidence function for the claudication event and for the event other injuries and estimates obtained for the Cox regression model for the cause-specific hazard of claudication and for the cause-specific hazard for other injuries.

\begin{tabular}{|c|c|c|c|c|}
\hline \multirow{3}{*}{ Covariable } & \multicolumn{2}{|c|}{$\begin{array}{c}\text { Fine and Gray Model for Subdistribution } \\
\text { hazard }\end{array}$} & \multicolumn{2}{|c|}{ Cox model for cause-specific hazard } \\
\hline & \multicolumn{4}{|c|}{ Event: claudication } \\
\hline & $p$-Value & SHR (I.C 95\%) & $\mathrm{p}$-Value & CHR (I.C 95\%) \\
\hline Sex & $0.4236^{\text {ns }}$ & $1.2114[0.7553 ; 1.9378]$ & $0.6732^{\mathrm{ns}}$ & $1.1052[0.6943 ; 1.7593]$ \\
\hline Age & $0.0146^{*}$ & $0.9479[0.9081 ; 0.9895]$ & $0.0062^{*}$ & $0.9485[0.9133 ; 0.9851]$ \\
\hline Weight & $0.3523^{\text {ns }}$ & $1.2408[0.7875 ; 1.9549]$ & $0.2932^{\text {ns }}$ & $1.2736[0.8133 ; 1.9992]$ \\
\hline Season & $0.0006^{*}$ & $1.3868[1.1501 ; 1.6723]$ & $<0.0001^{*}$ & $1.4564[1.2261 ; 1.7299]$ \\
\hline \multirow{2}{*}{ Covariable } & \multicolumn{4}{|c|}{ Event: other injuries } \\
\hline & $p$-Value & SHR (I.C 95\%) & $p$-Value & CHR (I.C 95\%) \\
\hline Sex & $0.3902^{\text {ns }}$ & $0.6951[0.3033 ; 1.5934]$ & $0.3350^{\text {ns }}$ & $0.6706[0.2976 ; 1.5109]$ \\
\hline Age & $0.5982^{\mathrm{ns}}$ & $1.0133[0.9648 ; 1.0642]$ & $0.9856^{\mathrm{ns}}$ & $1.0004[0.9560 ; 1.0469]$ \\
\hline Weight & $0.7514^{\mathrm{ns}}$ & $1.1411[0.5042 ; 2.5823]$ & $0.5148^{\text {ns }}$ & $1.3091[0.5821 ; 2.9438]$ \\
\hline Season & $0.5571^{\mathrm{ns}}$ & $1.1113[0.7813 ; 1.5808]$ & $0.0519^{\text {ns }}$ & $1.3888[0.9973 ; 1.9340]$ \\
\hline
\end{tabular}

CHR: cause-specific hazard ratio. SHR: subdistribution hazard ratio. I.C 95\%: 95\% confidence interval for the hazard ratios and the subdistribution hazard ratio. ${ }^{*}$ significant to $5 \%$. ns: not significant.

Regarding the event of other injuries, none of the studied covariates significantly affects the incidence and the cause-specific hazard. For claudication, in turn, the increase in age significantly decreases the probability of incidence of claudication (SHR $=0.9479$; $\mathrm{p}$-value $=0.0146)$ and the cause-specific hazard $(\mathrm{CHR}$ $=0.9485, \mathrm{p}$-value $=0.0062$ ) for claudication, that is, the risk of claudication when the risk of the competing event ("other injuries") is not considered.

Descriptive studies on training-related musculoskeletal injuries report that injury rates vary between age groups, with the highest levels being reported in two-year-old animals (Lindner \& Dingerkus, 1993). Notwithstanding, caution is advised in interpreting the results of these studies, as they may be influenced by confounding factors, such as exposure to training and running, which may influence the relationship between age and risk of injury (Cogger et al., 2006). The covariate stations significantly increased the incidence $(\mathrm{SHR}=1.3868, \mathrm{p}$-value $=0.0006)$ and the cause-specific hazard $(\mathrm{CHR}=1.4565$, $\mathrm{p}$-value $<0.0001)$ for claudication, with no significant effect for other injuries.

When competing risks were present, the effect of covariates on the cause-specific hazard and subdistribution hazard would be generally different and opposite. However, in a situation where there is an effect that decreases (or increases) the cause-specific hazard of the event of interest, with no significant effect on the cause-specific hazard of the competing event, there would be a decrease (or increase) in the incidence of the event of interest (Beyersmann et al., 2012). This behavior was verified for the covariates age and stations.

Regarding the differences in the significance of the effect of covariates on the cause-specific hazard, Bimali \& He (2015), in their study on the association between obesity and cancer risk, found a statistically significant higher cause-specific hazard for the obese population. Notwithstanding, the incidence of cancer was not statistically higher in this population. According to the authors, a statistically higher cause-specific hazard does not mean a high incidence rate of this event. Thus, the influence of covariates on the causespecific hazard may differ from the influence on the probability of occurrence of an event (Gillam et al., 2011).

Generally, the relationship between covariates and the cause-specific hazard cannot be translated into a direct relationship with the subdistribution hazard (Andersen et al., 2012). Nevertheless, the increase and decrease of the cause-specific hazard was translated into the subdistribution hazard. An explanation for this fact is found on the aforementioned argument of Beyersmann et al. (2012).

\section{Conclusions}

The incidences for claudication and other injuries obtained based on the Kaplan-Meier estimator overestimated the cumulative incidence functions for the respective events. The total incidence obtained by the sum of incidences for each of the events, derived from the Kaplan-Meier estimator, was biased.

The evaluated covariates have equally affected (increasing or decreasing) the subdistribution hazard, that is, the cumulative incidence function and the cause-specific hazard for the claudication event. This was due to these covariates having no effect on the competing event.

The approach based on standard survival analysis when competing events are present was inadequate. The competing risk approach was shown to be a more appropriate alternative.

\section{Acknowledgements}

To the Foundation for Research Support of Minas Gerais (FAPEMIG) for granting financial support to the research, and to the "ad hoc" rapporteurs of this article for the valuable suggestions and corrections. 


\section{References}

Aalen OO, Borgan O, Gjessing HK (2008) Survival and event history analysis: a process point of view. Springer Science \& Business Media. $539 \mathrm{p}$.

Andersen PK, Geskus RB, Witte T, Putter H (2012) Competing risks in epidemiology: possibilities and pitfalls. International Journal of Epidemiology 41(2): 861-870.

Assane C (2015) Análise de dados de sobrevivência na presença de riscos competitivos, Novas Edições Acadêmicas. $104 \mathrm{p}$.

Austin PC, LEE DS, Fine JP (2016) Introduction to the analysis of survival data in the presence of competing risks. Circulation 133(6):601-609.

Berry SD, Ngo L, Samelson EJ, Kiel DP (2010) Competing risk of death: an important consideration in studies of older adults. Journal of the American Geriatrics Society 58(4):783-787.

Beyersmann J, Schumacher M, Allignol A (2012) Competing risk and multistate models with $R$. Springer Science \& Business Media. $245 \mathrm{p}$.

Bimali M, He J (2015) Association between obesity and cancer: An analysis using the competing risk regression approach. Advances in Epidemiology 2015: 7p. DOI: http://dx.doi.org/10.1155/2015/132961

Carvalho MS, Andreozzi VL, Codeço CT, Campos DP, Shimakura SE (2011) Análise de sobrevivência: teoria e aplicações em saúde. Fiocruz. 432 p.

Cogger N, Evans D, Perkins N, Hodgson D, Reid S (2006) Risk factors for injuries in thoroughbred racehorses. $54 p$.

Colosimo EA, Giolo SR (2006) Análise de sobrevivência aplicada. $370 \mathrm{p}$.

Crowder MJ (2001) Classical competing risks. CRC Press. $186 \mathrm{p}$.

Fine JP, Gray RJ (1999) A proportional hazard model for subdistribution of a competing risk. Journal of the American Statistical Association 94(446):496-509.

Geskus RB (2015) Data analysis with competing risks and intermediate states. Chapman \& Hall/CRC. 243 p.
Gillam MH, Salter A, Ryan P, Graves SE (2011) Different competing risks models applied to data from the Australian Orthopaedic Association National Joint Replacement Registry. Acta Orthopaedica 82(5):513 $-520$.

Gooley TA, Wendy L, Crowley J, Storer BE (1999) Estimation of Failure probabilities in the presence of competing risk: New representations of old estimators. Statistics in Medicine 18(6):695 - 706.

Kaplan EL, Meier P (1958) Nonparametric estimation from incomplete observation. Journal of the Statistical Association 53(282):457-481.

Kim HT (2007) Cumulative incidence in competing risks data and competing risks regression analysis. Clinical Cancer Research 13(2): 559-565.

Lindner A, Dingerkus A (1993) Incidence of training failure among thoroughbred horses at Cologne. Germany Preventive Veterinary Medicine 16(2): 85-94.

Logan BR, Zhang MJ, Klein JP (2006). Regression models for hazard rates versus cumulative incidence probabilities in hematopoietic cell transplantation data. Biology of Blood and Marrow Transplantation. 12(1): 107-112.

Pintilie M (2006) Competing risk: a pratical perspective. John Wiley \& Sons. $224 \mathrm{p}$.

Putter H, Fiocco M, Geskus RB (2007) Tutorial in biostatistics: competing risks and multi-state models. Statistics in Medicine 26(11): 2389-2430.

R Development Core Team. R: A language and environment for statistical computing. Vienna, Austria: $\mathrm{R}$ Fundation for Statistical Computing, 2016. Disponível em: http://www.r-project.org/.

Scrucca L, Santucci A, Aversa F (2010) Regression modeling of competing risk using $R$ : an in-depth guide for clinicians. Bone Marrow Transplantation 45(91): 1388-1395.

Wolbers M, Koller MT, Stel VS, Schaer B, Jager KJ, Leffondre K, Heinze G (2014) Competing risks analyses: objectives and approaches. European Heart Journal 35(42): 2936-2941.

Wolbers M, Koller MT, Witteman JCM, Steyerberg EW (2009) Prognostic models with competing risks: methods and application to coronary risk prediction. Epidemiology 20(4): 555-561. 